\title{
Comprehensive Comparative Analysis on Export Competitiveness of Vegetable Industry among Provinces in China
}

\author{
Xiaoli Zhang \\ Foreign languages Department \\ Shandong Institute of Business and Technology \\ Yantai, China 264005
}

\begin{abstract}
By means of dimensional index variables, scientific selection of objects for comparative analysis and factor score analysis, the comprehensive comparative analysis of the competitiveness of inter provincial vegetable exports was carried out according to the mean value of the major vegetable export provinces from 2008 to 2016.
\end{abstract}

Keywords-vegetable industry; export competitive-ness; factor analysis

\section{INTRODUCTION}

The characteristics of modern agriculture are obviously the highest standards and requirements for testing the development level of vegetable industry, that is, the level of competitiveness. The realization of the goal of sustainable development of vegetable industry is also the stage standard and requirement for the modernization of vegetable industry. However, there are differences in the degree of agricultural modernization in different regions, and the specific characteristics of modern agriculture also show the heterogeneity of each other, which is difficult to distinguish by a unified and unique standard. Therefore, it is very necessary to measure the relative degree of modernization of vegetable industry in different regions through dimensional index variables and by referring to the competitive index value between industry competitors. [1]

\section{INDEX SYSTEM FOR EVALUATING EXPORT COMPETITIVENESS OF VEGETABLE INDUSTRY}

Based on the degree of difficulty in obtaining data and the degree of difficulty in establishing the comparative object, this study mainly analyzes the level of export competitiveness among provinces, and intends to select the top 10 provinces in the national vegetable export volume in recent years, including Shandong, Fujian, Jiangsu, Yunnan, Zhejiang, Hubei, Guangdong, Liaoning, Henan, Guangxi. Export competitiveness mainly reflects the market effectiveness of the industry in the international market. Eight indicators are selected to reflect the effectiveness of the international market, that is, international market share, dominant comparative advantage index, trade specialization index, export advantage variation index export quality upgrade Index, export dependency, export contribution, import share. The index number is less than the sample number in 10 provinces.

The meaning of each index is $\mathrm{X} 1$ : International market share, X2: dominant comparative advantage index, X3: trade specialization index, $\mathrm{X} 4$ : export advantage variation index, X5: export quality upgrade index, X6: export dependency,X7: export contribution, X8:import share. "Table I" is shown in the following.

TABLE I.

INDEX VALUE OF SHANDONG VEGETABLE EXPORT COMPETITIVENESS FROM 2008 TO 2016

\begin{tabular}{|c|c|c|c|c|c|c|c|c|}
\hline province/index & X1 & $\mathbf{X 2}$ & $\mathbf{X 3}$ & $\mathbf{X 4}$ & X5 & X6 & $\mathbf{X 7}$ & X8 \\
\hline shandong & 4.689 & 6.186 & 0.955 & -1.525 & 1.657 & 0.520 & 2.537 & 0.062 \\
\hline Fujian & 1.261 & 2.571 & 0.869 & -4.924 & 1.336 & 0.409 & 1.036 & 0.123 \\
\hline jiangsu & 0.831 & 0.423 & 0.988 & -0.730 & 1.380 & 0.087 & 0.172 & 0.001 \\
\hline Yunnan & 0.602 & 14.239 & 0.977 & 5.399 & 1.018 & 0.318 & 5.785 & 0.083 \\
\hline Zhejiang & 0.683 & 0.561 & 0.931 & -11.468 & 1.291 & 0.113 & 0.227 & 0.019 \\
\hline Hubei & 0.508 & 4.311 & 0.999 & 60.290 & 4.914 & 0.109 & 1.872 & 0.001 \\
\hline Guangdong & 0.616 & 0.189 & 0.833 & -12.597 & 1.429 & 0.067 & 0.077 & 0.009 \\
\hline Liaoning & 0.416 & 1.336 & 0.952 & -7.391 & 1.159 & 0.113 & 0.538 & 0.015 \\
\hline guangxi & 0.234 & 4.026 & 0.999 & 5.066 & 1.921 & 0.093 & 1.636 & 0.001 \\
\hline
\end{tabular}




\section{EVALUATION OF EXPORT COMPETITIVENESS OF VEGETABLE INDUSTRY IN VARIOUS PROVINCES}

The main sources of data in this paper are the Information Network of the Development Research Center of the State Council, the global market database (GMID), the statistics of the website of the Ministry of Commerce and relevant research documents.

\section{A. Calculation of Average Values of Indicators over the Years and Data Standardization Processing}

Test data for factor analysis by means of software stata10.0, KMO value is 0.5233 , so the original variable is suitable for factor analysis according to Kaiser's KMO metrics. According to the results of the analysis, only the first three principal components have eigenvalues greater than 1 and explain $86.085 \%$ of 8 Variable combination variance, so the first 3 factors are extracted. The eigenvalue of the first common factor extracted is 3.292 , accounting for
$41.15 \%$ total variance of 8 indexes; the eigenvalue of second common factors is 2.563; accounting for $32.04 \%$ total variance of 8 indexes; the eigenvalue of second common factors is 1.031 , accounting for $12.88 \%$ total variance of 8 indexes. In order to simplify the factor structure further, the main factor results are obtained by rotation according to the maximization of variance after extracting the factor. Based on the rotation variance interpretation, the variance contribution of the first and second common factors extracted decreased slightly, and the variance contribution of the third common factor increased slightly, which makes the difference of variance contribution average and reasonable; while the cumulative variance contribution rate of the three common factors extracted is $86.08 \%$ and not changed. "Table II" [2]

Based on the explanation of variance after rotation in "Table II", a formula for calculating the comprehensive scores of common factors can be constructed.

$$
\mathrm{F}=0.3056 \mathrm{~F} 1+0.2836 \mathrm{~F} 2+0.2717 \mathrm{~F} 3
$$

TABLE II.

TABLE OF CONTRIBUTION OF CHARACTERISTIC ROOT AND VARIANCE OF COMMON FACTOR BEFORE ROTATION

\begin{tabular}{|c|c|c|c|c|c|c|}
\hline \multicolumn{4}{|c|}{ Initial interpretation } & \multicolumn{3}{|c|}{ Extraction factor interpretation(after rotation ) } \\
\hline $\begin{array}{c}\text { common } \\
\text { factor }\end{array}$ & eigenvalue & $\begin{array}{c}\text { Variance contribution } \\
\text { rate }(\%)\end{array}$ & $\begin{array}{c}\text { Cumulative } \\
\text { contribution rate }(\%)\end{array}$ & eigenvalue & $\begin{array}{c}\text { Variance } \\
\text { contribution rate }(\%)\end{array}$ & $\begin{array}{c}\text { Cumulative } \\
\text { contribution rate }(\%)\end{array}$ \\
\hline F1 & 3.292 & 41.15 & 41.15 & 2.449 & 30.56 & 30.56 \\
\hline$F 2$ & 2.563 & 32.04 & 73.20 & 2.268 & 28.36 & 58.91 \\
\hline F3 & 1.031 & 12.88 & 86.08 & 2.173 & 27.17 & 86.08 \\
\hline F4 & 0.694 & 8.68 & 94.76 & & & \\
\hline F5 & 0.244 & 3.05 & 97.81 & & & \\
\hline F6 & 0.173 & 2.16 & 99.97 & & & \\
\hline F7 & 0.002 & 0.03 & 100 & & & \\
\hline F8 & 0.000 & 0.00 & 100 & & & \\
\hline
\end{tabular}

\section{B. Modeling}

Based on the results of the analysis "Table III", an expression for extracting common factors can be constructed, for example, $\mathrm{F} 1=-0.007 * \mathrm{X} 1+0.971 * \mathrm{X} 2+\ldots+0.453 * \mathrm{X} 8$, the method of constructing the expressions of F2 and F3 is consistent with that of F1. The factor load coefficient of F1 is maximum in variables $\mathrm{X} 2 、 \mathrm{X} 7 、 \mathrm{X} 8$; the factor load coefficient of $\mathrm{F} 2$ is maximum in variables $\mathrm{X} 5 、 \mathrm{X} 4$; the factor load coefficient of F2 is maximum in variables X6.

TABLE III.

FACTOR LOAD MATRIX AFTER ROTATION

\begin{tabular}{|l|l|l|l|}
\hline index & F1(Factor1) & \multicolumn{1}{|c|}{ F2(Factor2) } & F3(Factor3) \\
\hline $\boldsymbol{X} \mathbf{1}$ & -0.007 & 0.016 & 0.922 \\
\hline $\boldsymbol{X} \mathbf{2}$ & 0.971 & 0.072 & 0.176 \\
\hline $\boldsymbol{X} \mathbf{3}$ & 0.389 & 0.662 & -0.249 \\
\hline $\boldsymbol{4}$ & 0.205 & 0.890 & -0.057 \\
\hline $\boldsymbol{X} \mathbf{5}$ & -0.112 & 0.902 & -0.113 \\
\hline $\boldsymbol{X} 6$ & 0.392 & -0.196 & 0.891 \\
\hline $\boldsymbol{X} \mathbf{7}$ & 0.968 & 0.095 & 0.176 \\
\hline $\boldsymbol{X} \boldsymbol{8}$ & 0.453 & -0.415 & 0.624 \\
\hline
\end{tabular}

The standardized data (slightly) of the provincial index values "Table I" were brought into the expressions of the extracted common factors F1F 2 and F3, and the evaluation values of the extracted factors in each province were obtained "Table IV".
TABLE IV.

Evaluation VALUE OF PRINCIPAL FACTOR BY PROVINCE

\begin{tabular}{|c|l|l|l|}
\hline province & \multicolumn{1}{|c|}{ F1 } & \multicolumn{1}{|c|}{ F2 } & F3 \\
\hline Shandong & 0.046 & 0.320 & 2.394 \\
\hline Hebei & -0.162 & -0.925 & 1.161 \\
\hline Henan & -0.564 & -0.384 & -0.485 \\
\hline Jiangsu & 2.636 & -0.603 & -0.333 \\
\hline Sichuan & -0.619 & -0.605 & -0.371 \\
\hline Hubei & 0.0176 & 2.269 & -0.089 \\
\hline Henan & -1.031 & -0.981 & -0.352 \\
\hline Guangdong & -0.345 & -0.522 & -0.579 \\
\hline Liaoning & -0.252 & 0.954 & -0.493 \\
\hline Guangxi & 0.274 & 0.133 & -0.852 \\
\hline
\end{tabular}

\section{Computing Result}

The comprehensive score of vegetable industry in each province can be obtained by substituting the data of each factor score of "Table IV" into the calculation formula of common factor comprehensive score "Table V". 
TABLE V.

COMPREHENSIVE SCORE OF EXPORT

COMPETITIVENESS OF VEGETABLE INDUSTRY FROM HIGH TO LOW (BY AVERAGE)

\begin{tabular}{|c|l|}
\hline Region & Comprehensive score \\
\hline Shandong & 0.7553 \\
\hline Hubei & 0.6247 \\
\hline Yunnan & 0.5440 \\
\hline Henan & 0.0596 \\
\hline Fujian & 0.0036 \\
\hline Guangxi & -0.1102 \\
\hline Jiangsu & -0.3151 \\
\hline Liaoning & -0.4112 \\
\hline Zhejiang & -0.4617 \\
\hline Guangdong & -0.6891 \\
\hline
\end{tabular}

\section{CONCLUSION}

According to Table 4, using factor score analysis method, according to the mean value of each major vegetable export province from 2008 to 2016, we conducted a comprehensive comparative analysis of vegetable export competitiveness between provinces. From a single factor score, we found that Shandong vegetable industry is outstanding in the dominant comparative advantage index and export contribution rate; in trade specialization index, export advantage index, export quality upgrade index and other indicators, Shandong vegetable industry is better; in the international market share, export dependence and import share, Shandong vegetable industry has an absolute advantage. Judging from the comprehensive score, Shandong Province ranks first in the score, but Hubei Province, which ranks second in the overall score, is very close to the comprehensive score of Shandong, which indicates that Shandong vegetable industry export competitiveness is facing great competition pressure.

Through the comparative analysis of inter provincial, the comprehensive level of export competitiveness of Shandong vegetable industry is far higher than that of other provinces, in which there are many important enabling factors and experiences. After more than 20 years of development, the vegetable industry in Shandong has become one of the pillar industries in the agricultural industry of Shandong, and its comprehensive competitiveness in the country has always been in the "leading" position. The sustainable development goals of the vegetable industry and the maintenance of a high level of competitiveness are positively correlated with each other. This paper holds that the scale of the industry depends on the huge domestic demand market, whereas broad-scale market determines that only the production scale and trade scale of vegetable industry can keep its competitive advantage; farmers' choice of agricultural technology is the basic means to control the quality and safety of agricultural products, and the benefits generated by advanced agricultural technology are positively consistent with the goal of agricultural product quality and safety; in the sustainable development of the agricultural industry, including the vegetable industry, the governments plays an indispensable or irreplaceable role to provide external environment for the industry development, including basic guarantee for talents, funds, technology and institutions.[3]

\section{REFERENCES}

[1] Zhu Zhiqiang, Zhang Xiaoli. An Analysis of the Contributing Factors to the Export Competitive Advantage of Shandong Vegetable Industry. $[\mathrm{J}]$. Modern Agricultural Science and Technology, ,2013,(12):267-268.

[2] Zhu Zhiqiang. Analysis of the basic characteristics of vegetable Industry Development in Shandong Province. [J] .North horticulture 8: 222-223.

[3] He Qiwei, Jiao Zigao, Zhou Xuyuan, Liu Shiqi. Shandong Vegetable Science and Technology Work Review and Suggestion [J]. China Vegetables, 2014, (1): 61-65. 